\title{
RC infilled building performance against the evidence of the 2016 EEFIT Central Italy post-earthquake reconnaissance mission: empirical fragilities and comparison with the FAST method
}

\author{
Flavia De Luca ${ }^{1}$ (D) Gregory E. D. Woods $^{1} \cdot$ Carmine Galasso $^{2} \cdot$ \\ Dina D'Ayala ${ }^{2}$
}

Received: 2 June 2017/Accepted: 30 November 2017/Published online: 12 December 2017

(C) The Author(s) 2017. This article is an open access publication

\begin{abstract}
Damage data on low-to-mid-rise Reinforced Concrete (RC) buildings, collected during the UK Earthquake Engineering Field Investigation Team post-earthquake reconnaissance mission on the August 24 Central Italy earthquake, are employed to derive empirical fragility relationships. Given the small dataset, the new data distributions are used for the Bayesian update of fragility functions derived for the L'Aquila earthquake (same seismic region and similar construction typologies). Other properties such as number of storeys, age of construction and shape in plan of the buildings are also analyzed. This information is employed to assess the ability of the FAST method to predict damage states in non-regular infilled RC buildings for the municipalities of Amatrice, Accumoli, Arquata del Tronto and Norcia, all severely affected by the 2016 Central Italy sequence. FAST is a spectral-based method to derive capacity curves and peak ground acceleration damage state thresholds for buildings. It is a dedicated methodology for regular RC frame buildings with masonry infills, first calibrated on damage data from the 2009 L'Aquila earthquake and applied to the 2011 Lorca (Spain), the 2012 Emilia (Italy) events for damage backanalyses. The new data from the August 2016 Central Italy earthquake provide a test-bed for FAST further employments in case of less homogenous building samples. The application of FAST presented here accounts for different shake-maps produced by both the United States Geological Survey and the Italian National Institute of Geophysics and Volcanology which are significantly different and representative of different refinements of the demand scenario. For the area of Amatrice, where the two shake-maps provide similar estimates and the buildings considered match reasonably well the typology for which FAST is calibrated, the comparison between damage level observed and as provided by
\end{abstract}

Flavia De Luca

flavia.deluca@bristol.ac.uk

1 Department of Civil Engineering, University of Bristol, Queen's Building, University Walk, Bristol BS8 1TR, UK

2 Department of Civil Environmental \& Geomatic Engineering, University College of London, Chadwick Building, Gower Street, London WC1E 6BT, UK 
FAST is very satisfactory. For other structural typologies like RC industrial structures and dwellings with non-hollow-clay-bricks as infills, FAST needs further calibration.

Keywords August 2016 Italy earthquake · EMS98 · Observational fragility curve $\cdot$ FAST method $\cdot$ Reinforced concrete $\cdot$ Masonry infills

\section{Introduction}

In the aftermath of an earthquake, emergency responders face the daunting task of determining how to best deploy their resources to minimise the losses from the event (e.g. death, downtime, and economic losses) and assure a prompt recovery. To this aim, it is essential they can quickly evaluate the impact of an event on critical infrastructure and residential areas, or, more generally, the potential impact of future seismic events. The challenge of hindcasting (predict) damage from data quickly available after an earthquake event is still an unsolved issue in earthquake engineering (e.g. Douglas et al. 2015).

In the study presented here, information collected during the UK Earthquake Engineering Field Investigation Team (EEFIT) post-earthquake reconnaissance mission of the 24 August 2016 Central Italy earthquake (EEFIT 2016) was used to create a damage database of 42 Reinforced Concrete (RC) buildings from the municipalities of Amatrice, Accumoli, Norcia and Arquata del Tronto. These buildings were damaged during the earthquake, and are all located within the epicentral area of the considered event. Field data are used for two different objectives investigating two novel approaches for the use of field damage data, with the overall aim of a better prediction of expected damage on $\mathrm{RC}$ structures in the aftermath of an earthquake.

First, the data are used to derive fragility relationships using the procedure set out by Porter et al. (2007a, b), and more recently used by Liel and Lynch (2012) and De Luca et al. (2015) for Slight, Moderate and Heavy damage states as per European Macroseismic Scale, EMS-98 in the following (Grünthal 1998). Given the relatively limited amount of observations, the main objective here is first to derive fragility functions for the sake of comparison with those available for RC buildings derived from the larger datasets of L'Aquila 2009 damage records (i.e. Liel and Lynch 2012 and De Luca et al. 2015), and, then, to implement a Bayesian updating of those fragility functions by including the additional information provided by the new data (e.g., Miano et al. 2016). The regression parameters of the new earthquake data are employed, providing a novel interpretation of the consolidated Bayesian update of fragilities with respect to other studies (e.g., Singhal and Kiremidjian 1998; Porter et al. 2007a; Jaiswal et al. 2011; Miano et al. 2016).

Secondly, the FAST method, calibrated on L'Aquila damage data of regular infilled RC buildings (De Luca et al. 2015) is applied to verify its applicability to less homogenous samples of non-regular RC infilled buildings. The applicability of FAST to the broader context of Central Italy is inspected through a one-to-one comparison of building damage estimation for the 42 buildings considered. The 42 buildings are a very inhomogeneous sample including infilled RC frame typologies different from the regular clay-hollow brick infilled RC buildings considered for FAST calibration made on the L'Aquila data. Furthermore, even if the buildings are from the same region (i.e., Apennine area of Central Italy), they also refer to completely different urbanization contexts. L'Aquila is the main city of the Abruzzo region with more than 70,000 inhabitants, while the towns struck by the 2016 August earthquake (Accumoli, Arquata del Tronto, Norcia and Amatrice) are towns with a population ranging from less than 1000 up to 5000 inhabitants (Demo Istat 
2016). This can result, sometimes, in less standardized design protocols and different construction practices.

The FAST method (De Luca et al. 2014, 2015) provides a powerful approach for large scale vulnerability assessment of regular infilled Reinforced Concrete (RC) buildings, but it still requires calibration for different locations and broader structural typologies. In fact, FAST allows the definition of a simplified capacity curve for a given RC infilled building (or for a class of buildings) and a quick estimation of the damage level of the considered buildings up to heavy damage level (damage state 3, or DS3) according to EMS-98 (Grünthal 1998). It was applied to Italian and Spanish earthquake damage data collected in the aftermath of the events occurred in L'Aquila 2009 (Italy), Lorca 2011 (Spain) and Emilia 2012 (Italy), see De Luca et al. (2014, 2015), and Manfredi et al. (2014) for further details.

The most probable damage state according to FAST method for the buildings is evaluated considering as demand the Peak Ground Acceleration (PGA) provided by both the shake-maps of the event from the United States Geological Survey (USGS 2017) and the Italian National Institute of Geophysics and Volcanology (INGV 2017). The first one is representative of the accuracy obtainable straight after an event (e.g. less than an hour after the event occurred), while the second one accounts for more refined information and processing, typically implemented weeks later the event occurrence (Faenza et al. 2016). The comparison of damage data with FAST damage estimation according to both shakemaps provides insights on potential improvements of the method. The one-to-one comparison, pursuable thanks to the limited extension of the database, represents the best approach for the refinement of the method.

In the following, Sect. 2 provides some general information on the 2016 Central Italy full sequence, even if the study herein is limited to the August 24 earthquake, since damage data were collected before the occurrence of the later events (i.e., mid-October 2016). Section 3 describes the main characteristics of the database of 42 buildings collected during the mission. Section 4 provides the derivation of empirical fragilities and the Bayesian update of L'Aquila relationships. Section 5 investigates the comparison with the FAST method, discussing its potential applicability to non-regular RC infilled buildings, not limited to hollow clay brick infills. Finally, Sect. 6 summarises the main findings of the study, highlighting its limitations and envisaging developments for future studies.

\section{The event}

\subsection{Central Italy earthquake}

Over the period from the 24th August 2016 to the 18th January 2017, the Central Italy region, close to the town of Amatrice, was hit by five different earthquakes with magnitude higher than 5.5, causing large scale destruction of buildings, damage to infrastructure and landslides, reducing the town of Amatrice to rubble. The first event of the sequence occurred close to the city of Amatrice on the 24th August 2016; it was of moment magnitude $\left(\mathrm{M}_{\mathrm{w}}\right) 6.2$ according to the USGS (6.0 according to INGV). Two $\mathrm{M}_{\mathrm{w}} 5.5$ and $\mathrm{M}_{\mathrm{w}} 6.1$ events occurred on the 24th of October 2016 close to the City of Norcia, with another $\mathrm{M}_{\mathrm{w}} 6.6$ (6.5 according to INGV) event occurred later on the 30th of October close to the city of Preci. On the 18th January 2016, a fifth $M_{w} 5.7$ earthquake struck the area 




Fig. 1 Location of the five events with $M_{w} \geq 5.5$ of the 2016 Central Italy sequence occurred between August 2016 and January 2017. Magnitude estimation and epicentre locations are based on USGS data. (Reproduced with permission from USGS 2017)

close to the city of Amatrice. Figure 1 shows the five earthquake locations and the magnitude evaluations according to USGS (2017).

\subsection{Amatrice earthquake 24th August 2016}

The earthquake struck at 01:34 (3:36 local time) in the early morning of the 24th of August 2016, close to the city of Amatrice, causing 292 deaths in the towns of Amatrice, Accumoli and Arquata del Tronto and displacing 2925 people, (Relief Web 2017).

Amatrice is a town with a total population of approximately 2600 people (Demo Istat 2016). Most buildings in the region are masonry structures built prior to 1984 (Del Gaudio et al. 2017). Within the region, there is a large variance in building earthquake resistance because of changes in the regional hazard classification. In 1984, the seismic classification of the region was changed from zone 3 to zone 2, and in 1998 the area was changed to zone 1 (see also Lai et al. 2009; Ricci et al. 2011). It is worth noting that L'Aquila was classified as zone 2 in 1915, so from 1984 up to 1998 the design requirements for the two areas were the same. After 2003 (OPCM 3274 2003; OPCM3431 2005), a new seismic classification was introduced representing the first significant upgrade towards the Eurocode 8 approach; an elastic spectral shape was provided, more accurately taking into account soil amplification and topography. Finally, in 2008 (DM 14/01/2008), a bespoke seismic classification was introduced in Italy and, since then, spectral shape and spectral ordinates are evaluated on the basis of the uniform hazard spectrum computed on a 5-by-5 km grid (http://esse1. mi.ingv.it/). Prior to 2003, the first, second and third seismic categories in Italy, were characterized by a design peak ground acceleration (PGA) of $0.10,0.07$ and $0.04 \mathrm{~g}$, respectively (Manfredi et al. 2014), when the allowable stress method was used for design. Two coefficients, $\varepsilon(1.0-1.3)$ and $\beta(1.0-1.2)$, were used to account for soil compressibility and presence of structural walls. Regarding seismic input, even if different new seismic 
design codes were approved later (DM 3/3/1975; DM 24/1/1986; DM 16/1/1996), no changes were introduced regarding this aspect. On the other hand, in this period, the Limit State method was introduced and, for Ultimate Limit State, the design accelerations listed above were supposed to be increased by a factor of 1.50 (see Ricci et al. 2011 for further details).

These changes increased the design forces for new buildings in the area. Post-Earthquake reconnaissance surveys (e.g. EEFIT 2016; EERI 2016; GEER 2016) showed that the majority of buildings with medium to heavy damage were constructed prior to 1984 (see Fig. 2). The most frequent damage observed in this area was heavy and very heavy (e.g. Fig. 2a, b) and occurrence of brittle failures in structural elements (e.g. Fig. 2c) was the most frequent structural damage observed in $\mathrm{RC}$ buildings inspected in the area. The vast majority of the buildings were designed according to obsolete seismic design codes and so, they are non-compliant with the current Italian Seismic code (DM 14/01/2008, 2008).

The three closest stations recording the 24th August event were AMT in Amatrice, RQT in Arquata del Tronto and NOR in Norcia (see Fig. 3). The station ACC in Accumoli recorded some of the other events of the sequence but it was non-functional on the 24th of August. The station AMT recorded a PGA of $850 \mathrm{~cm} / \mathrm{s}^{2}$ in the East-West direction (EW) (Luzi et al. 2016). The records for this event provided by RQT station were of low quality (Luzi et al. 2016), which means that the signal from this station could not be used for FAST analysis, and more in general for other engineering analyses. According to ITACA database (http://itaca.mi.ingv.it/), Eurocode 8 soil characterisation of these stations (CEN 2004) is made on the basis of geological map data; i.e., the soil class is flagged with an asterisk (*) in ITACA. AMT and RQT are classified as soil class B*, ACC is classified as $\mathrm{A}^{*}$ and NOR is classified as $\mathrm{C}^{*}$.

The USGS and INGV shake-maps show significant differences. The INGV shake-map in the municipality of Arquata del Tronto (including the low town of Arquata, the locality of Arquata Borgo and the locality of Tino) has a lower PGA with respect to that of USGS.

The two shake-maps are generated with the software package ShakeMap ${ }^{\circledR}$ developed by the US Geological Survey Earthquake Hazards Program (Wald et al. 2006) and also implemented by the INGV for the evaluation of shake-maps (Michelini et al. 2008). The INGV map shown here includes revisited data (including the identification of the fault plane projection), while the USGS one is very similar to the first map released by INGV right after the event. Further details on the differences in PGA maps, when more refined information is included, are reported in Faenza et al. (2016). In the context of this study,



(a)

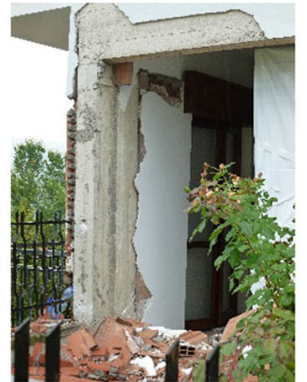

(b)



(c)

Fig. 2 Damage to RC buildings a, b very heavy damage to masonry infills, c shear failure in column, building ID 12 Lat 42,37,33.198N, Long. 13,17,25.944; source EEFIT (2016) 


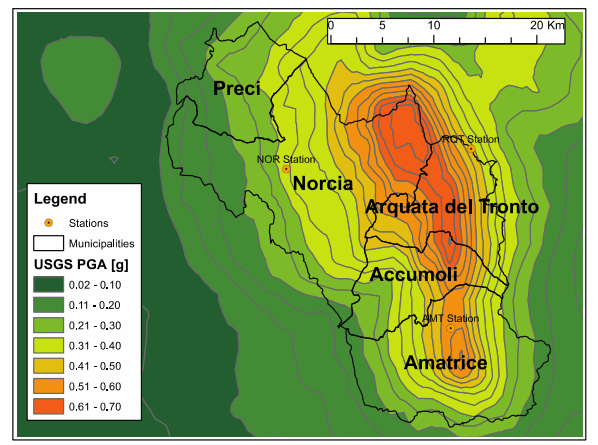

(a)

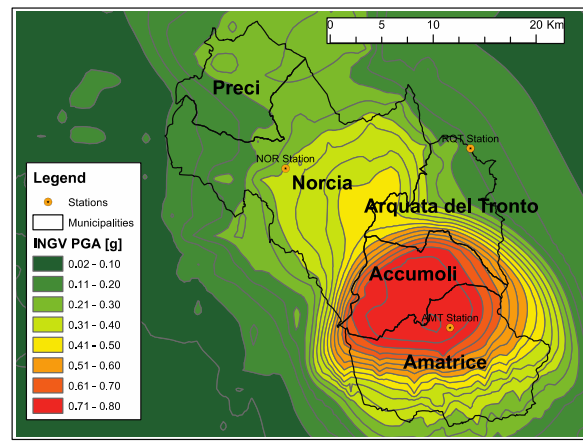

(c)

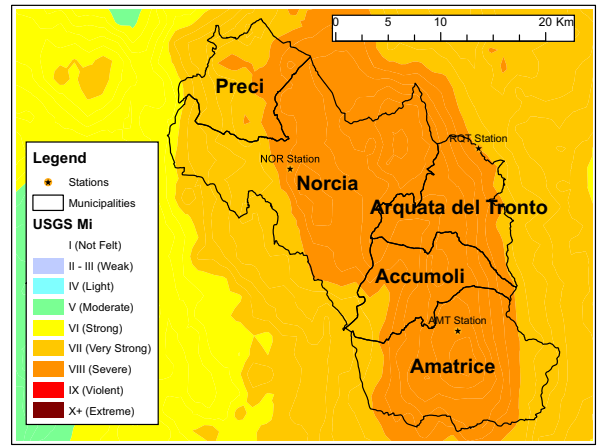

(b)

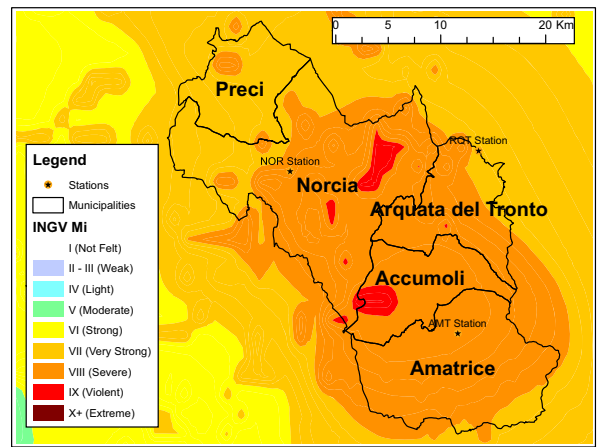

(d)

Fig. 3 Shake-map according to USGS $\left(M_{w} 6.2\right)$ for a PGA and $\mathbf{b}$ Macroseismic Intensity, and accoding to INGV $\left(M_{w}\right.$ 6.0) for $\mathbf{c}$ PGA and $\mathbf{d}$ Macroseismic Intensity (Shake-maps downloaded on 29/03/2017)

both maps are used since the USGS datum represents a quickly available datum better compliant to the main scope of FAST method (i.e., the rapid assessment of damage), while the INGV datum is a more accurate description of the shaking accounting for more detailed data that became available some weeks after the earthquake.

\section{RC building data}

The database considered here includes buildings surveyed during the 2016 EEFIT mission to Central Italy (EEFIT 2016). The buildings are all RC, mainly moment-resisting-frames, with different types of masonry infills. The data was gathered through field work using the EEFIT Rapid Visual Survey Form (EEFIT 2016). The form has three sections; the first records the GPS coordinates, which were used in conjunction with Google maps to locate the buildings in a Geographical Information System (GIS) so that their PGA, Area, Perimeter and Shape could be determined from satellite maps (Bing Aerial 2016). The second section of the form gathers structural information about the building; it includes the gravitational and lateral load resisting system, construction materials, number of stories, age of construction, and the presence of vertical or plan irregularities. This part of the form also includes the building classification according to PAGER (Porter et al. 2008). Where possible, data relating to specific details such as through thickness of infills and presence of 
retrofitting was also gathered. The third part of the form assessed the overall damage state according to the EMS-98 scale and listed the primary and secondary damage observed. Photos were taken for each one of the buildings and paired with GPS coordinates.

Data collected during the EEFIT mission were all included in a shape file and overlaid to the shakemaps provided by USGS and INGV (see in Fig. 4 data location and damage classification overlaid to the USGS shake-map). The vast majority of structures were classified as C3 (Non-ductile reinforced concrete frame with masonry infill walls), and a very limited amount classified as C1 (Ductile reinforced concrete moment frame with or without infill) according to PAGER classification (Porter et al. 2008).

The buildings in the database have one to six storeys, with the majority having between one and two storeys (57\%) (Fig. 5a). This is a common feature of the building stock in the area and differs substantially from databases of RC buildings collected after the 2009 L'Aquila earthquake; i.e., 20\% in Liel and Lynch (2012), 10\% in De Luca et al. (2015). The reason for this is in the rural versus urban setting of the two areas, as already pointed out in Sect. 1. Most of the buildings in the database were constructed in the period between 1976 and 1998 (Fig. 5b) which does match with De Luca and Liel and Lynch. The age of construction bins in Fig. 5b were chosen to reflect the changes in the risk classification of the region between 1984 and 1994. The buildings in each different bin had been built according to different codes of practice (Ricci et al. 2011). Finally, the transverse ratios in plan $\left(\mathrm{L}_{\mathrm{x}} / \mathrm{L}_{\mathrm{y}}\right)$ for the 2016 database (Fig. 5c) are more evenly distributed than those collected for L'Aquila in De Luca et al. (2015); in this study, $60 \%$ of buildings have a $\mathrm{L}_{\mathrm{x}} / \mathrm{L}_{\mathrm{y}}$ value between one and two compared with $88 \%$ of those inspected in De Luca et al. The distribution of $\mathrm{L}_{\mathrm{x}} / \mathrm{L}_{\mathrm{y}}$ indicates how the 42 buildings in the cities of Amatrice, Accumoli, Arquata del Tronto and Norcia are less regular in plan than those considered in De Luca et al. (2015). The $\mathrm{L}_{\mathrm{x}} / \mathrm{L}_{\mathrm{y}}$ information is not available for the Liel and Lynch's database, but it is a relevant datum to the FAST method (see Sect. 5).

Half of the buildings considered in this study were surveyed in Arquata del Tronto municipality including the locality of Low Arquata, Arquata Borgo, Tino (among others) as shown from the maps in Fig. 4a, d and e. In Fig. 6a, data per municipality are shown. The damage rate by municipality, shown in Fig. 6b, matches reasonably with the Macroseismic Intensity (MI) maps showed in Fig. 3c, d, as the greatest rates of damage occurred in Amatrice, where most of the fatalities occurred during the earthquake, and Arquata del Tronto (both MI grade VIII). MI maps of USGS and INGV provide same estimates for the area of Amatrice, and for the area of Arquata del Tronto municipality in which the vast majority of the buildings are located.

Most of the buildings in the sample are residential buildings (Fig. 7a, b) and have between one and three stories (Fig. 7b), but some of the buildings are different. Four of the buildings are not residential buildings, but industrial buildings, such as those in Fig. 7c, d, which have several differences compared to the rest of the sample. These buildings are still included in the sample since they are cast-in-place structures and they have continuous beam-column joints. They are more similar to the typical cast-in-place residential RC buildings of medium-high seismic areas, such us the Apennine region of Central Italy, rather than being similar to the Italian industrial buildings found in low seismic areas like the Emilia region (see Ercolino et al. 2016).

Several buildings in the sample are irregular in plan, with high $\mathrm{L}_{X} / \mathrm{L}_{Y}$. The infills are made out of concrete, and the heights of the single story are greater than $3.0 \mathrm{~m}$, one of the assumptions made in the FAST application (see Sect. 5). These buildings had a lower damage level than other buildings in Arquata del Tronto municipality, which has the effect of bringing down the probability of damage used to generate the fragility curves (Table 2). 


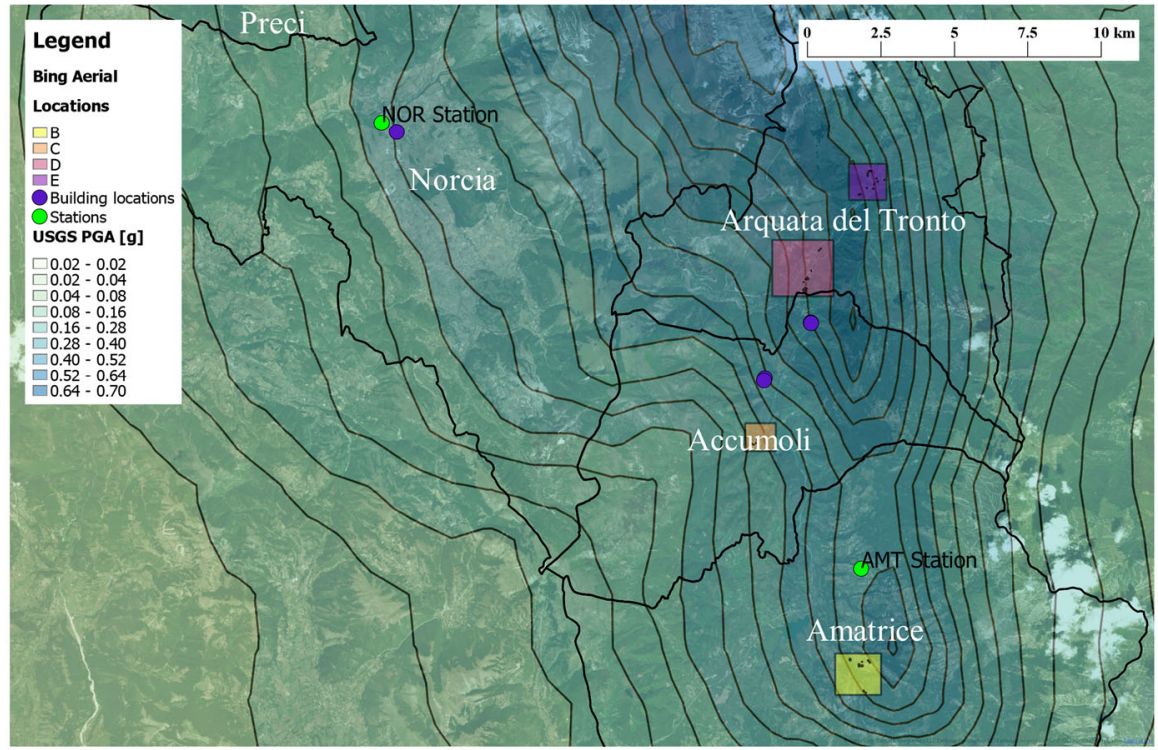

(a)

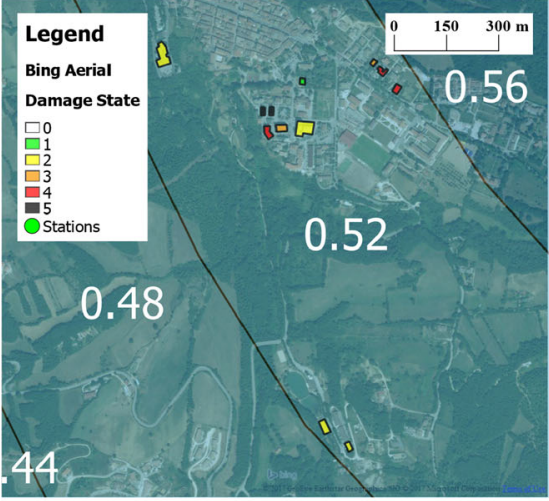

(b)



(d)

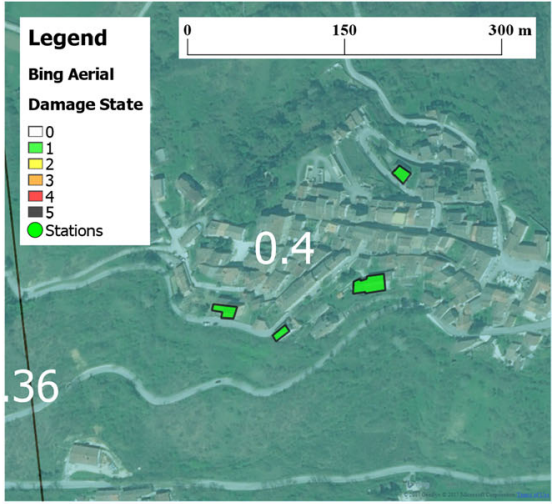

(c)

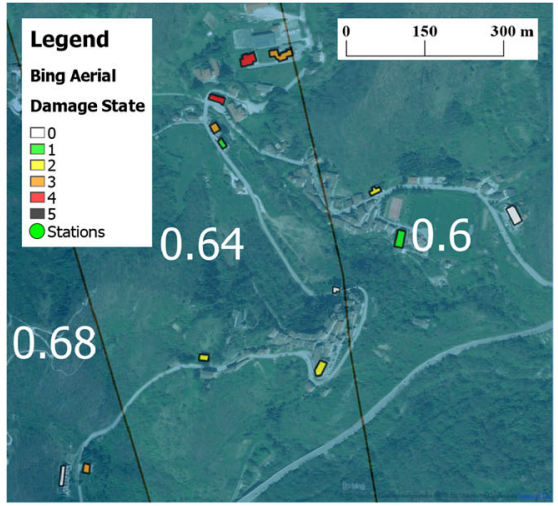

(e) 
4 Fig. 4 Location of the buildings a zoomed areas and buildings not shown in these areas; zoom on b Amatrice, c Accumoli, d, e Arquata del Tronto municipalities, all overlaid to USGS PGA shake-map contours

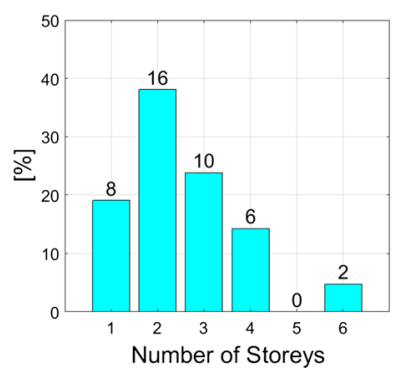

(a)

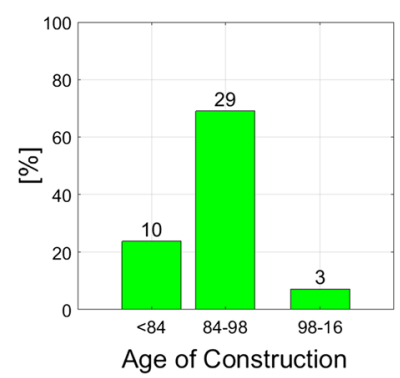

(b)

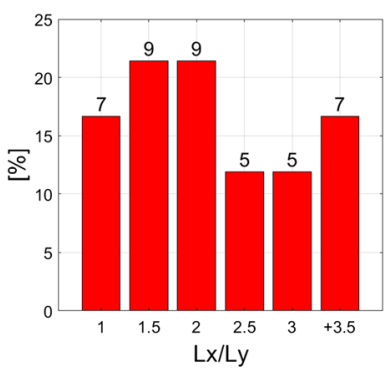

(c)

Fig. 5 Properties of buildings surveyed, a number of stories, $\mathbf{b}$ age of construction, $\mathbf{c}$ shape ratio between the two principal dimensions in plan (i.e. Lx and Ly)

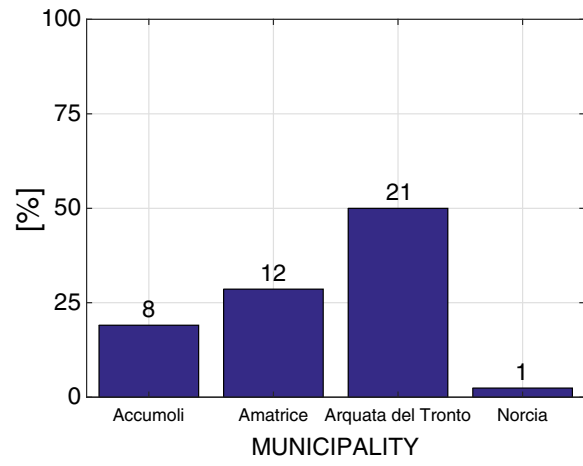

(a)



(b)

Fig. 6 a Number of buildings and $\mathbf{b}$ the damage state represented per municipality

\section{Empirical fragility relationships}

Empirical or observational fragility functions are based on post-earthquake surveys, and they express the likelihood of different levels of damage sustained by a structure class as function of a ground motion intensity measure, or IM (Rossetto et al. 2013). They are expressed in different mathematical forms and can be based on observation data from one or more earthquakes. Even if sample sizes vary from 20 (Sarabandi et al. 2004) up to hundreds of thousands of data (e.g., Yamaguchi and Yamazaki 2001), a suitable sample size can be considered 200 or above (Rossetto et al. 2013).

Herein, all the fragility relationships assume a lognormal distribution and they are expressed in the form of Eq. 1 as the probability that damage $D$ exceeds the ith damage state (DSi) given the PGA (herein used as an IM), where $\eta$ and $\beta$ are the mean and standard deviation of the variable's logarithm, in this case indicated as pga and normally distributed.

For the sake of comparison with other fragility functions on RC buildings in L'Aquila, the PGA was considered as IM, herein. It is worth noting that the spectral acceleration for 


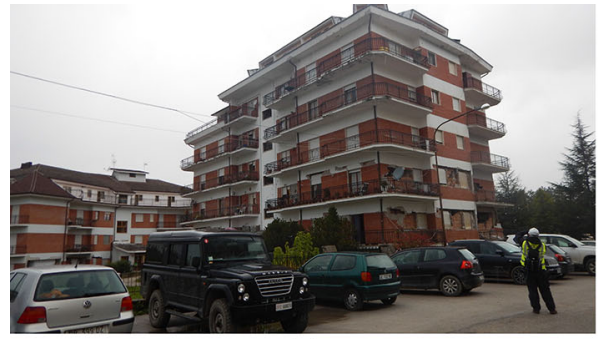

(a)

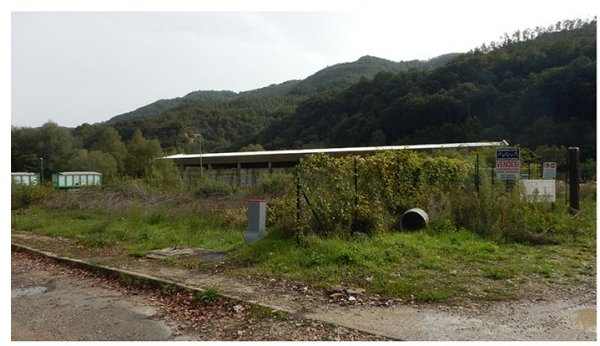

(c)

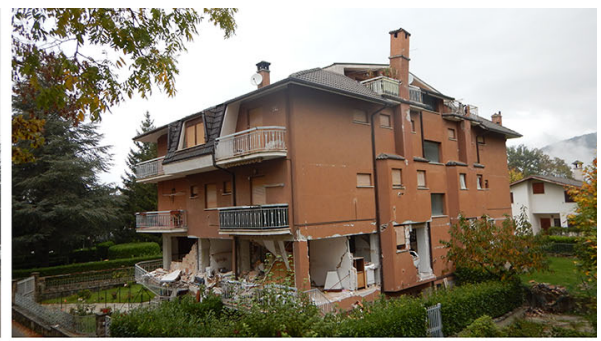

(b)

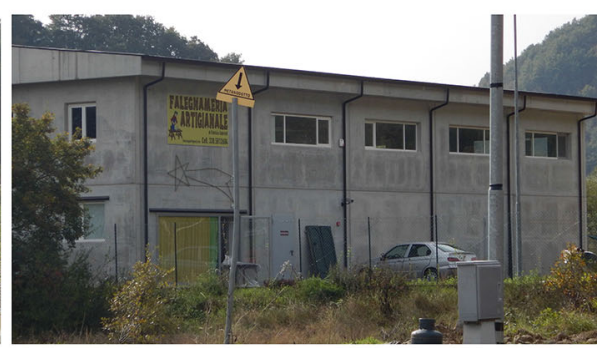

(d)

Fig. 7 Residential buildings from Amatrice a building ID 13, Lat. 42,37,33.564N Long. 13,17,27.714E; b building ID 20, Lat. 42,37,36.690N Long. 13,17,40.416E; c an industrial storage building in Arquata del Tronto, building ID 37 Lat. 42,44,42,42.180N Long. 13,16,4.440E and d a office building from the same site, building ID 39 Lat 42,44,39.360N Long. 13,16,1.818E. Source EEFIT (2016)

$0.3 \mathrm{~s}$ would be a better IM for the category of mid-rise buildings, and it has showed a better correlation especially for high damage levels and for ductile structures (Rossetto et al. 2013). On the other hand, here the focus is on damage states from one to three and mainly on non-ductile reinforced concrete frame with masonry infill walls, so the use of PGA is acceptable.

$$
P(D \geq D S i \mid p g a)=\Phi\left(\frac{\ln (p g a / \eta)}{\beta}\right)
$$

\subsection{Empirical fragilities}

The 42 damage-data represents a very limited sample to derive reliable fragility curves. On the other hand, these limited data can be still useful for the sake of comparison with more robust relationships and for Bayesian updating.

The data are analysed using the method outlined in Porter et al. (2007b) and employed in Liel and Lynch (2012) and De Luca et al. (2015) for analysing damage data of buildings during the 2009 L'Aquila earthquake. The RC buildings of this study are first sorted into PGA-contours. As discussed, the shake-maps in terms of PGA from the USGS (Fig. 3a) and the INGV (Fig. 3c) show significant differences in their values, especially for the municipality of Arquata del Tronto where $50 \%$ of buildings is located. Based on this, a preliminary analysis was done for both shake-maps pooling the data into 3 bins with a PGA averaged over the different PGA-contours. However, the INGV based bins did not produce usable results; there was no possibility to derive a linear regression with positive slope with INGV's PGA data. 
Hence only the USGS shake-map is used in the following to carry out observational fragility assessment for sake of comparison with other regional fragilities. As mentioned in Sect. 2, INGV's PGA datum can be more accurate since it is subjected to a further manual check including more refined information on the fault; on the other hand, USGS's PGA is available online right after an event (i.e. more suitable for rapid vulnerability applications to be employed in the aftermath of an event).

The empirical fragility curves for this dataset were generated using the USGS shakemap (Fig. 8). Table 1 shows the distribution of data over the three bins considered. Figure 8 a shows the probability of exceeding a specific damage state for the three bins.

To generate the fragility curves, inverse normal probability of the damage state occurring for each bin is plotted against the natural logarithm of the average PGA experienced for each bin. The probability of failure for each DSi is calculated as the number of buildings with an equal or greater damage state $\left(n_{\text {build-exc DSi }}\right)$ plus one divided by the total number of building $\left(n_{\text {build-tot }}\right)$ plus one, see Eq. 2. A linear regression is then fitted through the points for each damages state assuming the equation $y=\log (P G A) \cdot q+p$, as shown in Fig. 8 b. The standard deviation of the logarithms $(\beta)$ is equal to $1 / \mathrm{q}$ and the median $(\eta)$ is equal to $\exp (-p / q)$. The two estimated parameters $\eta$ and $\beta$ allow the definition of fragility curves in terms of PGA in the form of Eq. 1.

$$
P(D \geq D S i \mid P G A)=\frac{n_{\text {build-excDSi }}+1}{n_{\text {build }- \text { tot }}+1}
$$

Although this procedure produces fragility curves, the limited size of the database results in some limitations. As it can be seen in Figs. 4 and 6a, most of the buildings are located in the Arquata del Tronto region, and they had very similar PGAs. This resulted in the necessity to have bins not equal in size, even if the correct practice would be to pool bins with approximately the same size. The limited size of Bin 1 meant that the probability of damage quickly falls close to zero, as seen in Table 2. This ended up in the two fitting points for DS2 and DS3 of Bin 1 overlapping (see Fig. 8b) and producing two crossing regression lines. However, Fig. 8a also shows that there is a good linear progression for the

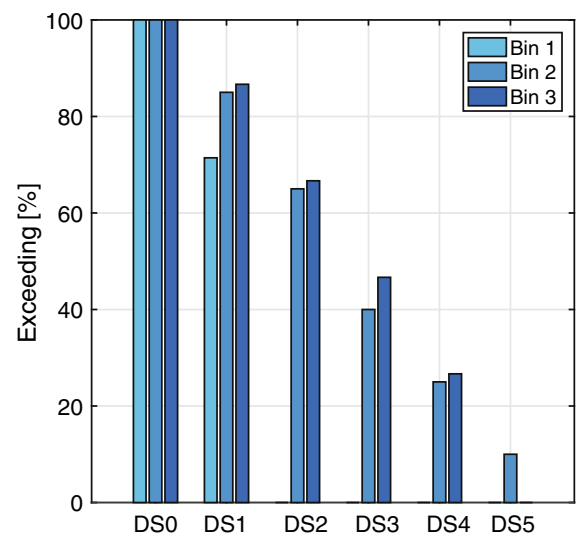

(a)

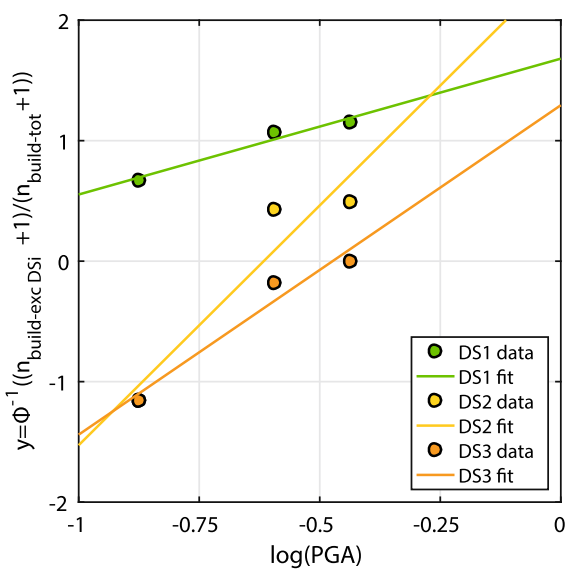

(b)

Fig. 8 a Percentage of buildings exceeding each damage state for each bin, b linear fit used for the generation of fragility curves as set out in Porter et al. (2007b) 
Table 1 PGA-bins and number of buildings of each damage state

\begin{tabular}{llllllllr}
\hline BIN & PGA & DS0 & DS1 & DS2 & DS3 & DS4 & DS5 & Total \\
\hline 1 & 0.42 & 2 & 5 & 0 & 0 & 0 & 0 & 7 \\
2 & 0.55 & 3 & 4 & 5 & 3 & 3 & 2 & 20 \\
3 & 0.65 & 2 & 3 & 3 & 3 & 4 & 0 & 15 \\
\hline
\end{tabular}

remaining bins for each damage state, allowing a computation of fragility curves for DS1, DS2 and DS3 out of the RC sample collected in the aftermath of the August event. If these fragility functions were used as independent empirical relationships the correction to avoid their crossing should be applied as discussed in Porter et al. (2007b); on the other hand, herein they are used for sake of comparison with other empirical relationships and to work as additional information, so no correction for their tail-crossing is applied.

A T-Student test (Ang and Tang 1984) is performed on the regression lines in Fig. 8b and the corresponding p-values are provided in Table 2. The T-Student test on the slope of the regression line for each curve is below the $2 \%$ significance level; it can be accepted with $98 \%$ confidence that each line represents a significant fit given the dataset.

\subsection{Comparison with L'Aquila observational fragilities}

The fragility curves generated using Porter et al.'s approach for the August 24 event data (Amatrice) are shown in Fig. 9, with comparison to those generated by Liel and Lynch (2012) and De Luca et al. (2015) for the L'Aquila 2009 earthquake. The $\eta$ and $\beta$ parameters for the three groups of fragilities are provided in Table 3.

In this study, for DS1, the $\eta$ is $0.25 \mathrm{~g}, \beta$ is equal to 0.89 and this high value results in a very poor comparison with the fragility curves for DS1 from De Luca et al. (2015) and Liel and Lynch (2012), see Fig. 9a. Such a high dispersion is atypical and it is caused by the limited amount of data, but still the central estimate can be useful for comparison with the previous studies. For DS2, $\eta$ is $0.54 \mathrm{~g}$, which is higher than that from De Luca et al. and Liel and Lynch, but the $\beta$, which is equal to 0.25 , is only slightly higher than the $\beta$ for DS2 proposed in De Luca et al. For DS3, $\eta$ is $0.62 \mathrm{~g}$, and $\beta$ is 0.37 , providing a median value that is significantly higher with respect to the median estimations provided in De Luca et al. and Liel and Lynch. In Fig. 9, the 95\% confidence intervals for the three new fragility functions obtained are also shown. Such intervals are obtained estimating the standard deviation $\left(\sigma_{\mathrm{DSi}}\right)$ of the linear regressions in Fig. $8 \mathrm{~b}$ as the ratio between the norm of the residuals and the square root of the degrees of freedom (in this case 3-2=1) for each regression line corresponding to the three damage states (Ang and Tang 1984). Such $\sigma_{\mathrm{DSi}}$ is employed to compute the $95 \%$ confidence regression line assuming the error term of the regression $\sigma_{\mathrm{DSi}}$ normally distributed with mean equal to zero and standard deviation equal

Table 2 T-Student slope regression test for each damage state

\begin{tabular}{llrr}
\hline Damage state & DS1 & DS2 & DS3 \\
\hline SE coefficient & 7.98 & 2.46 & 0.60 \\
Test statistic & 0.14 & 0.46 & 1.89 \\
$p$ value $[\%]$ & 1.08 & 1.27 & 1.69 \\
\hline
\end{tabular}




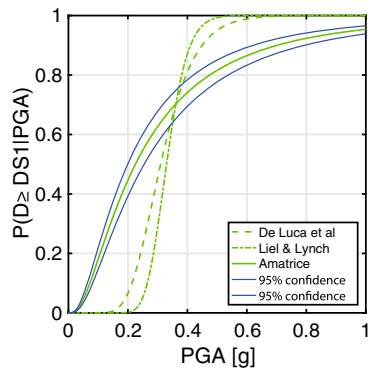

(a)

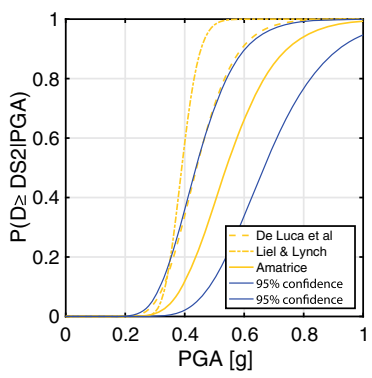

(b)

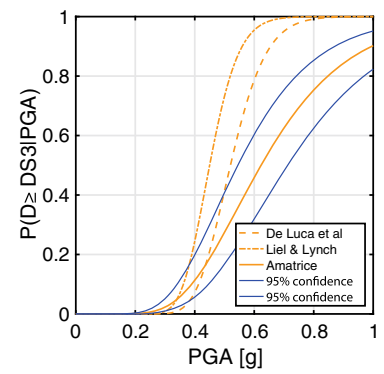

(c)

Fig. 9 Comparison of fragility curves for different damage states, a DS1, b DS2, and c DS3

Table 3 Comparison of the August 24 event fragilities carried out in this study with results from De Luca et al. (2015), Liel and Lynch (2012)

\begin{tabular}{|c|c|c|c|c|c|c|}
\hline \multirow[t]{2}{*}{ Source } & \multicolumn{2}{|l|}{ DS1 } & \multicolumn{2}{|l|}{ DS2 } & \multicolumn{2}{|l|}{ DS3 } \\
\hline & $\eta[\mathrm{g}]$ & $\beta$ & $\eta[\mathrm{g}]$ & $\beta$ & $\eta[\mathrm{g}]$ & $\beta$ \\
\hline Amatrice (this study) & 0.25 & 0.89 & 0.54 & 0.25 & 0.62 & 0.37 \\
\hline De Luca et al. (2015) & 0.31 & 0.29 & 0.44 & 0.23 & 0.52 & 0.18 \\
\hline Liel and Lynch (2012) & 0.33 & 0.17 & 0.39 & 0.12 & 0.45 & 0.17 \\
\hline
\end{tabular}

to $\sigma_{\mathrm{DSi}}$. This approach allows for the derivation of the fragility curves and their corresponding $\pm 95 \%$ confidence interval for comparison with the other fragilities from previous studies (i.e., Liel and Lynch 2012; De Luca et al. 2015).

With the exception of DS1 (for which the new estimate is not very reliable given the high standard deviation of the distribution), the median PGA for Amatrice is bigger with respect to the corresponding estimates made for L'Aquila. Furthermore, all the logarithmic standard deviations are higher than those computed for L'Aquila. The only exception is DS2, for which the De Luca et al's fragility is within the $95 \%$ confidence interval of that carried out in this study; this is due to the similar $\beta$ of the two lognormal distributions and the relatively small difference between $\eta$ (i.e. $0.44 \mathrm{~g}$ vs. 0.54 ) in the range of $20 \%$, see Fig. 9b.

The increased median PGA obtained for RC buildings of the Apennine region of Central Italy for DS2 and DS3 based on these new data provides an interesting insight. It was observed by Douglas et al. (2015) that the general trend of fragility functions for RC buildings applied to the case of L'Aquila provided an underestimation of damage when using "blind" scenarios (similar to the preliminary level of information provided by the USGS shake-map). Herein, the USGS blind scenario results in a similar trend for the vulnerability of mid-rise RC buildings for DS2 and DS3.

The above results, far from being conclusive, make the new fragility functions suitable to "adjust" the information carried out for L'Aquila earthquake. Thus, the new estimates can be used as additional information for Bayesian updating of the fragility curves derived for L'Aquila earthquake, providing a more robust insight into the vulnerability of RC infilled buildings mainly characterised by the obsolete seismic design typical of the Apennine region in Central Italy. The update of fragility curves as soon as new data 
is available is a well-known and consolidated practice (e.g., Singhal and Kiremidjian 1998; Porter et al. 2007a, b; Jaiswal et al. 2011; Miano et al. 2016).

The two fragilities functions by Liel and Lynch and De Luca et al. are the priors updated with the new data from the August 24 earthquake. If the prior and the new data are lognormally distributed, it is demonstrated (e.g., Singhal and Kiremidjian 1998; Miano et al. 2016) that the posteriors will be also lognormally distributed with the updated parameter $\eta^{\prime \prime}$ and $\beta^{\prime \prime}$ evaluated according to Eq. 3 and 4, respectively. The parameters $\eta_{\mathrm{p}}^{\prime}$ and $\beta_{\mathrm{p}}^{\prime}$ are the statistics of the prior distribution, $\eta_{1}$ and $\beta_{1}$ are the logarithmic mean and standard deviation describing the distributions of new data and $n$ is the number of observations. Singhal and Kiremidjian (1998) used this approach for the update of analytical fragilities with post-earthquake observational data expressed in terms of damage index. Miano et al. (2016) used the same formulation implementing as new data the resulting distribution obtained from the median PGAs of a number of fragility functions for regional bridges and evaluating the $\beta_{1}$ as the standard deviation of these PGAs, being $n$ the number of fragilities employed.

Herein, the regression results obtained in this study for DS1, DS2 and DS3 are assumed as new data for the update of L'Aquila fragilities on RC structures. So, $\eta_{1}$ and $\beta_{1}$ are the values obtained in Table 3 for this study, for each DS respectively. The number of observations is assumed equal to three, as it is the number of points on the basis of which the parameters in Eq. 3 and 4 are derived.

$$
\begin{gathered}
\eta_{p}^{\prime \prime}=\frac{\eta_{p}^{\prime} \cdot\left(\frac{\beta_{l}^{2}}{n}\right)+\eta_{l} \cdot \beta_{p}^{\prime 2}}{\left(\frac{\beta_{l}^{2}}{n}\right)+\beta_{p}^{\prime 2}} \\
\beta_{p}^{\prime 2}=\frac{\left(\frac{\beta_{l}^{2}}{n}\right) \cdot \beta_{p}^{\prime 2}}{\left(\frac{\beta_{l}^{2}}{n}\right)+\beta_{p}^{\prime 2}}
\end{gathered}
$$

The updated fragility curves for De Luca et al and Liel \& Lynch are compared in Fig. 10 and the new distribution parameters are shown in Table 4. The update reduces significantly the $\beta^{\prime \prime}{ }_{p}$ of the posteriors and, for both L'Aquila studies, the new $\eta^{\prime \prime}{ }_{p}$ are up to $16 \%$ higher for DS2 and DS3 and less than $5 \%$ lower for DS1. The lower value for the $\beta^{\prime \prime}{ }_{p}$ of the posteriors (i.e. resulting in steeper fragilities) is a common result when the update of the standard deviation of the logarithms is done though the expression of Eq. 4, see also Miano et al. (2016) as example. The new interpretation of the Bayesian updating formulation for lognormal priors and new lognormal data provides a very interesting application "to merge" the information coming from different empirical fragility results. The updated distributions carried out with this interpretation of Eq. 3 and 4 provides a powerful tool for the integration of empirical relationships characteristic of the same regional area but related to different earthquakes.

Furthermore, the comparison of the new posteriors, obtained from the two different studies on L'Aquila and updated with 2016 Central Italy damage data, emphasizes how the relative comparison of the $\eta^{\prime \prime}{ }_{p}$ for DS1 and DS2 for De Luca et al. and Liel and Lynch has remained roughly the same, while for DS3 the updated fragilities have become closer $\left(\eta^{\prime \prime}{ }_{p}=0.56 \mathrm{~g}\right.$ for the updated DS3 distribution of De Luca et al. vs. $\eta^{\prime \prime}{ }_{p}=0.52 \mathrm{~g}$ for the updated DS3 distribution of Liel and Lynch) making the damage prediction of DS3 of the two L'Aquila studies more homogeneous. 


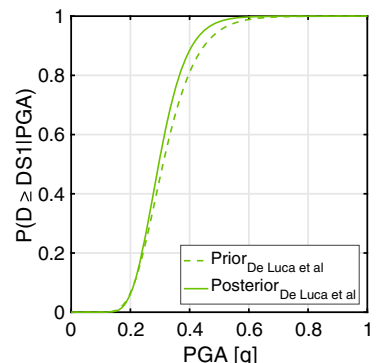

(a)

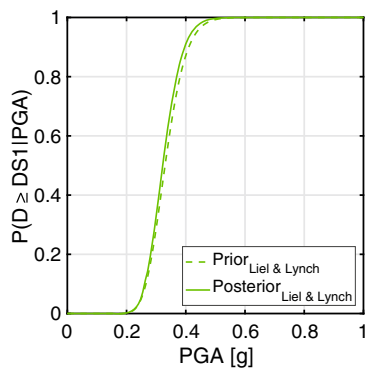

(d)

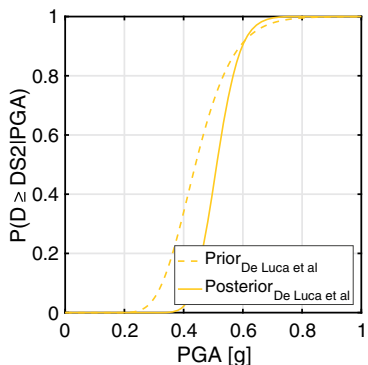

(b)

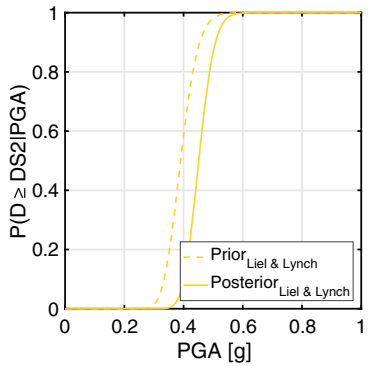

(e)



(c)

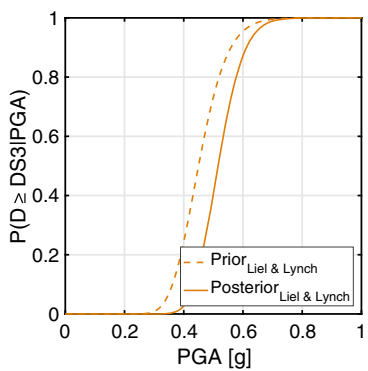

(f)

Fig. 10 Priors (dotted lines), and posteriors (solid lines) referred to a DS1, b DS2, c DS3 for De Luca et al.'s fragilities (2015), and referred to d DS1, e DS2, and f DS3 for Liel and Lynch's fragilities (2012)

Table 4 Posterior fragilities as per De Luca et al. (2015) and Liel and Lynch (2012) using the data of this study

\begin{tabular}{|c|c|c|c|c|c|c|}
\hline \multirow[t]{2}{*}{ Source } & \multicolumn{2}{|l|}{ DS1 } & \multicolumn{2}{|l|}{ DS2 } & \multicolumn{2}{|l|}{ DS3 } \\
\hline & $\eta[\mathrm{g}]$ & $\beta$ & $\eta[\mathrm{g}]$ & $\beta$ & $\eta[\mathrm{g}]$ & $\beta$ \\
\hline De Luca et al.- - updated & 0.30 & 0.25 & 0.51 & 0.12 & 0.56 & 0.14 \\
\hline Liel and Lynch-updated & 0.32 & 0.16 & 0.45 & 0.09 & 0.52 & 0.13 \\
\hline
\end{tabular}

The general physical consideration on the posterior fragilities in Fig. 10 is that the updating leads to less fragile buildings for DS2 and DS3. The field data underpinning the priors by Liel and Lynch and De Luca et al. refer to the city of L'Aquila only and to reasonably large populations of buildings. The information used for the updating refers to a small population of field data related to a different earthquake and to RC buildings sparsely distributed in a wider geographical area. The building populations related to the L'Aquila 2009 earthquake and to this earthquake share the overall construction practice and the fact of being located in the epicentral areas of two earthquakes referred to the Apennine region of Central Italy. The updating has shifted the median of the fragilities closer (but still significantly lower) to the empirical values of very large databases referred to large geographical regions and based on numerous earthquakes (e.g., Rossetto and Elnashai 2003) avoiding the significant increase of the standard deviation (too high for regional fragility curves). 


\section{FAST method}

FAST is a rapid vulnerability evaluation method that can be used as large-scale tool either for rapid response in the aftermath of earthquake events or for prioritising strengthening and retrofitting interventions on building stock. It has been calibrated for the case of 2009 $\mathrm{M}_{\mathrm{w}} 6.3 \mathrm{~L}$ 'Aquila earthquake (De Luca et al. 2015), and applied and compared with damage data of the $2011 \mathrm{M}_{\mathrm{w}} 5.1$ Lorca (Spain) earthquake (De Luca et al. 2014), and the $2012 \mathrm{M}_{\mathrm{w}} 6$ Emilia (Italy) earthquake (Manfredi et al. 2014).

RC buildings with masonry infills are a very common structural typology in Mediterranean countries and infills are typically made of hollow clay bricks. The use of hollow clay bricks increases the buildings lateral peak strength and stiffness (reducing the fundamental period of the building). This, in turn, can improve their performances during earthquakes, as long as the level of shaking is low enough to avoid their brittle collapse. In fact, once the masonry infills attain their peak capacity, the building has a significant drop in strength and stiffness and the RC primary load-carrying system becomes the only defence against further earthquake excitations (e.g. Kappos 2000, D'Ayala et al. 2009; Asteris et al. 2011; Ellul and D'Ayala 2012a, b).

\subsection{Overview of FAST}

The first step in the FAST methodology is to establish the capacity curve (CC) for each individual building, this curve assumes that critical damage will occur at the ground story and will occur from a soft-story collapse mechanism. This is a conservative hypothesis based on the evidence from post-earthquake investigations (e.g., Ricci et al. 2011), and from some general stiffness considerations related to the initial stiffness of RC buildings with masonry infills. Indeed, when the infills are initially un-cracked, their stiffness is significantly higher than the stiffness of the RC frame; so, the total stiffness along the height can be considered almost constant if infills have a reasonably regular distribution in height (e.g., no pilotis configuration at the first storey). This almost constant stiffness distribution against seismic storey-shear forces increasing from top to bottom storey makes very likely the occurrence of first cracking, and then of a collapse mechanism at the bottom storey (e.g., Fiorato et al. 1970; Fardis 1997). The above assumption is validated by the damage observed after the 2016 Central Italy earthquake (e.g., Figs. 2a, b and 7a, b) and in other field campaigns (e.g., Ricci et al. 2011; Manfredi et al. 2014).

The CC is defined in terms of the Spectral Acceleration and Spectral Displacement $\left(\mathrm{S}_{\mathrm{a}}-\mathrm{S}_{\mathrm{d}}\right)$ and it is defined using the following parameters:

- $\mathrm{C}_{\mathrm{s}, \max }$ - the inelastic acceleration of the equivalent single degree of freedom (SDOF) at which the maximum strength is obtained, see Eqs. 5 and 7.

- $\mathrm{C}_{\mathrm{s} \text {,min }}$-the inelastic acceleration of the equivalent SDOF at the attainment of the plastic collapse mechanism of the RC structure (all the infills of the storey involved in the mechanism have attained their residual strength), see Eqs. 6 and 7.

- $\mu_{\mathrm{s}}$-the available ductility up to the beginning of the degradation of the infills.

- T-the equivalent period computed from the elastic period $\mathrm{T}_{0}$ of the infilled building.

The value of $\mu_{s}$ is assumed equal to 2.5 and it is derived from studies on gravity load designed buildings (Verderame et al. 2012, 2014). This assumption reflects also the case of obsolete seismic design for residential buildings since their ductility is often limited by the 
occurrence of brittle failures (De Luca and Verderame 2013, 2015; Jalayer et al. 2015). The other parameters are defined as follows:

$$
\begin{gathered}
C_{s, \max }=\alpha \cdot C_{s, \text { design }}+\frac{\tau_{\max } \cdot \rho_{w}}{N \cdot m \cdot \lambda} \\
C_{s, \min }=C_{s, \text { design }}+\beta \cdot \frac{\tau_{\max } \cdot \rho_{w}}{N \cdot m \cdot \lambda} \\
C_{s, \text { design }}=S_{a, d}(T) \cdot R_{\alpha} \cdot R_{\omega}
\end{gathered}
$$

The variables are defined as:

- $\quad N$ is the number of storeys;

- $m$ is the average mass of each story normalized by the building area (assumed equal to $0.8 \mathrm{t} / \mathrm{m}^{2}$ ) (Verderame et al. 2012; De Luca et al. 2014);

- $\lambda$ is a coefficient for the evaluation of the first mode participation mass with respect to the total mass of the multi-degree of freedom (MDOF) according to Eurocode 8 (CEN 2004);

- $\tau_{\max }$ is the maximum shear stress of the infills according to Fardis (1997) and equal to 1.30 times the cracking shear stress of infills $\left(\tau_{\mathrm{cr}}\right)$;

- $\rho_{w}$ the ratio between the infill area $\left(\mathrm{A}_{\mathrm{w}}\right)$ evaluated along one of the principal directions of the building and the building area $\mathrm{A}_{\mathrm{b}}$;

- $\alpha$ coefficient that accounts for the RC elements strength contribution at the attainment of the infill peak strength;

- $\quad \beta$ coefficient that accounts for the RC elements residual strength contribution after the attainment of the plastic mechanism of the bare RC structure;

- $C_{s, \text { design }}$ the inelastic design acceleration coefficient of the bare RC structure, obtained from the obsolete design practice of the structures considered;

- $S_{a, d}(T)$ inelastic design acceleration as per obsolete codes (as inferred from the age of construction of the building);

- $R_{\alpha}$ structural redundancy factor;

- $R \omega$ over strength material factor, equal to 1.45 as based on Galasso et al. (2014)

- $T$ the equivalent period equal to $T_{O}$ (Eq. 8) multiplied by the amplification coefficient $\kappa$ (equal to 1.40).

More details on the assumptions made on the variables can be found in De Luca et al. (2014, 2015).

$$
T_{0}=0.023 \frac{H}{\sqrt{100 \cdot \rho_{w}}}=0.0023 \frac{H}{\sqrt{\rho_{w}}}
$$

The simplified capacity curve then allows to define an approximate Incremental Dynamic Analysis Curve (IDA or IN2). The CC and the IDA curves are related by a strength reduction factor-ductility-period $(R-\mu-T)$ relationship. Different $R-\mu-T$ relationships are available in literature, some of them are bespoke for masonry infilled buildings (Dolšek and Fajfar 2004), some other are more general for piecewise linear fits with softening behaviour (Vamvatsikos and Cornell 2006), both provided very close results for previous FAST applications. In this study, in analogy to what was done in De Luca et al. (2015), SPO2IDA tool was used (Vamvatsikos and Cornell 2006), allowing to construct a relationship between the elastic spectral acceleration $\left(S_{a}\right)$ and the SDOF displacement $\left(S_{d}\right)$. An example of CC and IDA curves can be seen in Fig. 11a; the CC is obtained through the 
parameters in Eqs. 5-11 specialised for the number of storeys and age of construction (2storey, age 84-98) of building 10. This approach allows to compute explicitly the uncertainty related to the $R-\mu-T$ (i.e. represented by the IDA curves at the three percentiles) and it is suggested for simplified nonlinear assessment of buildings according to the recent FEMA p-58 (2012).

As mentioned in Sect. 3 and showed in Fig. 5c, it was possible to identify the lengths in plan of each building from the GIS software. This allowed to compute two values of $\rho_{w}$ per building (one for each direction), that, in turn, resulted in a $T$, a CC and an IDA for each direction through the assumption of $20 \mathrm{~cm}$ thickness of the infills as per field observations made during the EEFIT mission and other field reconnaissance missions in Italy. As an example, in Fig. 11a, the CC and IDA for y direction (short direction) of building ID 10 are shown (i.e. $\mathrm{CC}_{\mathrm{y}}$ and $\mathrm{IDA}_{\mathrm{y}}$ ). With the IDA curve defined, the next step in FAST is to calculate the $S_{d \mid D S i}$ threshold for each damage state as per Eqs. 9 and 10.

The interstorey drift ratio (IDR) threshold per each damage state from one to three (i.e. $\mathrm{IDR}_{\mathrm{DSi}}$ ) is based on experimental data and assumed on the basis of the calibration made for L'Aquila earthquake in De Luca et al. (2015), as shown in Table 5. These IDRs are assumed to be attained at the first storey; this is the step of the method in which the firststorey-mechanism hypothesis is employed and the assumption of hollow clay bricks intervenes (i.e. IDR experimental ranges are based on clay hollow brick infills).

The IDR for the other storeys is computed considering an inverted triangular distribution of lateral forces as shown in Eq. 11, in which $H_{i}$ is height at the $i$ th story and $H_{j}$ is height at the $j$ th story above the level of application of the seismic action (foundation or top of a rigid basement). The coefficient $\gamma$ in Eq. 9, is the average of the ratio $K_{I} / K_{i}$ between the stiffnesses of the first storey $\left(K_{l}\right)$ and that of the $i$-th storey $\left(K_{i}\right)$, all evaluated considering the only infills' contribution and neglecting the concrete stiffness contribution at the different storeys, see De Luca et al. (2014) for details. The coefficient $\gamma$ is assumed as 1 for DS1 and as 0.4 for DS2 and DS3. The value of $\gamma=0.4$ for DS2 and DS3 was calibrated against L'Aquila damage data (De Luca et al. 2013) and it underpins the assumption of a linear degrading distribution of stiffness from the bottom storey up to the top, assuming the

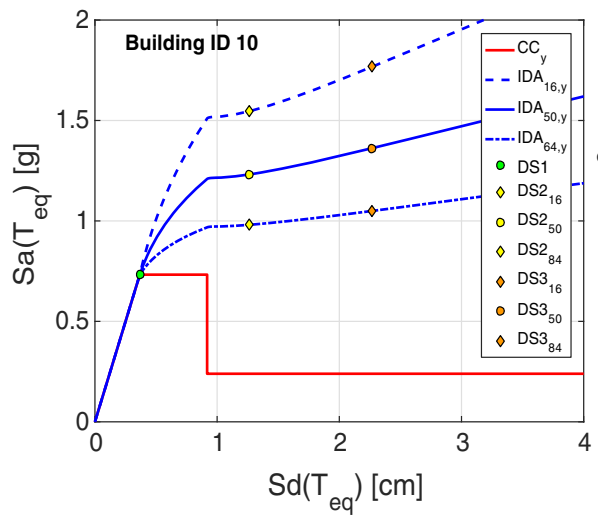

(a)

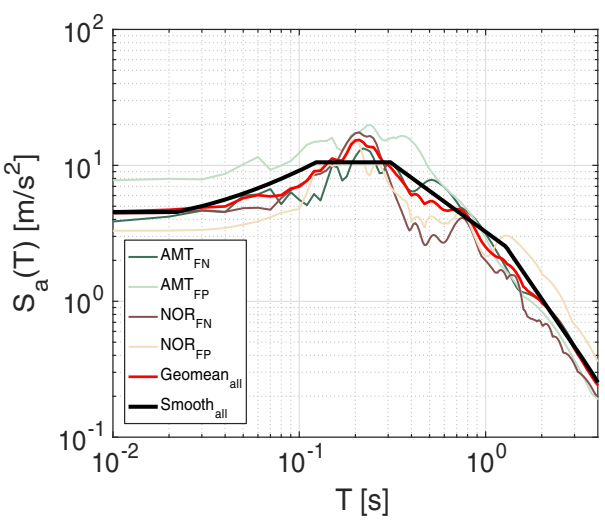

(b)

Fig. 11 a Example of capacity curve in the short direction (CCy), IDA curves at different percentiles and damage thresholds for DS1, DS2 and DS3 referred to building ID 10; b fault normal (FN) and fault parallel (FP) 5\% damped elastic spectra at the stations of Amatrice (AMR) and Norcia (NOR), their geometric mean $\left(\right.$ Geomean $\left._{\mathrm{all}}\right)$ and the smoothed spectrum $\left(\right.$ Smooth $\left._{\mathrm{all}}\right)$ according to Malhotra (2006) 
Table 5 IDR thresholds used for each damage state

\begin{tabular}{lll}
\hline $\mathrm{IDR}_{\mathrm{DS} 1}(\%)$ & $\operatorname{IDR}_{\mathrm{DS} 2}(\%)$ & $\operatorname{IDR}_{\mathrm{DS} 3}(\%)$ \\
\hline 0.1 & 0.4 & 0.8 \\
\hline
\end{tabular}

fully cracked stiffness of the infills at the bottom storey and the uncracked stiffness at the top storey (Gómez-Martínez et al. 2014). So, FAST method assumes an approximate deformed shape for the evaluation of the roof displacement of each building, and then it transforms the roof displacement into $S_{d}$ through the first mode participation factor $\left(\Gamma_{1}\right)$ coming from the tabulated values in ASCE/SEI41-06 (2007). The interstorey height is assumed equal to $3.0 \mathrm{~m}$, as it is frequent practice for RC buildings in Italy and considering that no detailed information was available for all the buildings in the sample. Figure 11a shows the $S d_{\mid D S i}$ providing, in turn, the corresponding $S a_{\mid D S i}$ through the IDA curves. It is worth noting that SPO2IDA provides three percentiles for the IDA estimation and, as soon as inelastic behaviour occurs in the building (i.e., excluding the case of DS1 that is assumed to occur always in the elastic branch of the curve), $S d_{1 D S 2}$ and $S d_{1 D S 3}$ intersect the three percentiles curves providing the estimate of $S a_{\mid D S 2}$ and $S a_{1 D S 3}$ at the $16^{\circ}, 50^{\circ}$, and $84^{\circ}$ percentiles.

$$
\begin{gathered}
S_{d \mid D S 1,2}=\frac{1}{\Gamma_{1}}\left(I D R_{D S 1,2} \cdot h_{\mathrm{int}}+\gamma \cdot \sum_{i=2}^{N} I D R_{i} \cdot h_{\mathrm{int}}\right) \\
S_{d \mid D S 3}=S_{d \mid D S 2}+\frac{\left(I D R_{D S 3}-I D R_{D S 2}\right) \cdot h_{\mathrm{int}}}{\Gamma_{1}} \\
I D R_{i}=I D R_{D S i} \cdot\left(1-\sum_{1}^{i-1} \frac{H_{i}}{\sum_{j=1}^{N} H_{j}}\right)
\end{gathered}
$$

The spectral acceleration at the fundamental period of the building, $S_{a}(T)$, can be converted into an equivalent PGA by using spectral scale factors, these are developed based on either a code or smooth spectral shape or the recorded response spectra (Manfredi et al. 2014; De Luca et al. 2014). In this study, a smooth spectral shape was obtained from the fault normal (FN) and fault parallel (FP) spectra recorded at AMT and NOR stations during the August 24 event, assuming a strike of 155 degrees (Luzi et al. 2016).

The smooth shape was computed according to the coefficients provided in Malhotra (2006). This procedure is similar to the Newmark-Hall procedure, but there are some important differences. First, the amplification factors are different. Second, the control periods are not absolute, they are relative to the "central" period of the ground motion, recognizing that the frequency-content can vary significantly from one ground motion to another, (Malhotra 2006). The same approach was used in the calibration of FAST method for L'Aquila earthquake (De Luca et al. 2015) and it results in a spectral shape accounting, in some way, for the characteristics of the ground motion of the event. This approach is preferable to the use of a code spectrum and to the use of a single record spectrum. In the first case, it is because the period of infilled buildings is often in the initial branch of the 
spectrum where Malhotra's shape provides a more accurate result with respect to a code shape that is generic and non-event-specific. In the second case, there is no single record reflecting properly the scaling factor for a broad area. The smoothed spectra $\left(\right.$ Smooth $\left._{\text {all }}\right)$ is computed from the geometric mean of FN and FP signals in AMT and NOR (Geomean ${ }_{\text {all }}$ in Fig. 11b). The geometric mean alone is still not suitable since its shape is jagged and it can lead to inconsistent results especially for samples like the one considered herein, in which the structures are distributed in a large area with a low number of recordings.

Entering in the smooth spectral shape with the period $T$ calculated for each direction of each building; it is possible to evaluate a spectral scaling factor between $S_{a}(T)$ and PGA to finally convert $S a_{\mid D S i}$ into $P G A_{\mid D S i}$ by dividing it for the scaling factor obtained. The period $\mathrm{T}$ considered is an equivalent period corresponding to the cracked stiffness of the building $\left(\mathrm{T}=\kappa \cdot \mathrm{T}_{0}\right)$ that reflects the average stiffness degradation from DS1 up to DS3. This approach replicates what is typically done in spectral-based methods (e.g., Calvi 1999; Crowley et al. 2004; Iervolino et al. 2007). The minimum $P G A_{\mid D S i}$ threshold per direction is assumed to be the PGA capacity of the building at the given damage state.

The $P G A_{\mid D S i}$ are compared with the PGA from the shake-map, obtaining the estimation of damage according to FAST. The method results in a damage estimation from DS0 up to the exceedance of DS3, since it does not provide any damage threshold for DS4 and DS5. From a practical point of view this is not a real limitation considering that exceedance of DS3 very likely result in the demolition of the structure given the level of structural damage that occurs starting form DS3 and the typically assumed repair-to-cost ratios exceeding 50\% for DS3, DS4 and DS5 (Erdik and Fahjan 2006).

\subsection{Application of FAST to 2016 Central Italy earthquake}

The FAST method is applied to the $42 \mathrm{RC}$ buildings considered in this study and the resulting damage state is evaluated considering both the PGA shake-maps of the USGS (Fig. 3a) and that of the INGV (Fig. 3c). The resulting distributions of damage can be compared with the observed damage. Note that all buildings with an observed damage equal or higher than DS3 are binned together, see Fig. 12.

In terms of estimating the overall number of damaged building, the USGS shake-map $\left(\mathrm{FAST}_{\mathrm{USGS}}\right)$ results in a damage distribution that tends to overestimate the damage; the number of predicted building in each damages state is lower, except in the $\geq$ DS3 bin, see

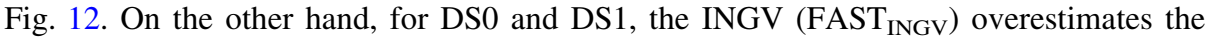
amount of buildings in these bins, thus underestimating the number of buildings for DS2, but it manages to predict the exact number of buildings for damage $\geq$ DS3. The aggregated trends per DS for the two FAST applications, shown in Fig. 12, reflect the differences in terms of shake map emphasized in Fig. 3a, c.

A building-to-building comparison for PGA demands of USGS and INGV is shown respectively in Figs. 13 and 14. All the cases in which FAST estimation is higher or equal than the observed are tagged as SAFE estimation (i.e. Damage Difference $\geq 0$ ). The cumulative residual difference over the 42 buildings (evaluated summing up algebraically the damage differences) is positive and equal to +16 using the USGS shakemap (see Fig. 13) and equal to - 10 using the INGV shakemap (see Fig. 14). This evidence allows saying that FAST overestimates damage if the USGS shake map is used and it underestimates damage if INGV shakemap is used. This is certainly due to the inherent difference in the two shake map estimations, but it is also due to the different accuracy of the methodology for different typologies that are distributed in different municipalities. 


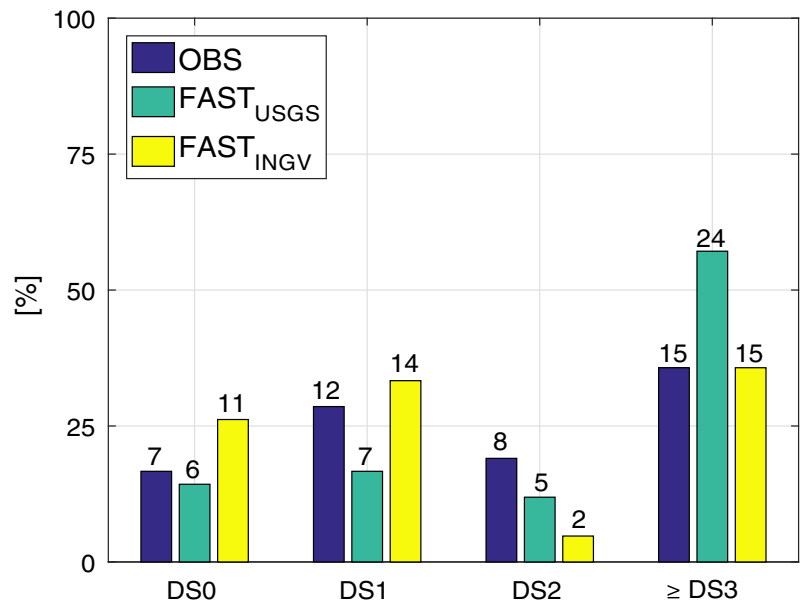

Fig. 12 Damage distribution comparison as observed from the field survey (OBS) and analytically computed according to FAST using the PGA demand of USGS (FAST USGS $_{\text {) and INGV (FAST }}$ INGV) as shown in Fig. 3a, c

Figure 13 shows that the $71 \%$ of FAST estimates equal or exceed the actual DS grade observed after the earthquake. Only three buildings (7\%) have their DS underestimated by two EMS grades. For the region of Amatrice, 50\% of the buildings have their DS estimated exactly; with only two buildings having more than one DS difference (building IDs 10 and $18)$.

Referring to the case of INGV shake-map demand (Fig. 14), the number of buildings in the safe estimation area is 59\%. For Amatrice, there are no buildings with more than one DS difference. In the sole case where $\mathrm{FAST}_{\mathrm{INGV}}$ underestimates the damage state for Amatrice, the building was not a residential building but a sort of industrial building with significant part of the external infills take up by windows (see Fig. 15a); so, a limited lateral strength was contributed by the infills and it did not fully comply with the hypotheses of FAST. For the INGV shake-map demand, FAST was unable to provide safe predictions for the damage state in Arquata del Tronto municipality. This is caused by lower PGAs in the INGV shake-map with respect to the USGS one for Arquata del Tronto

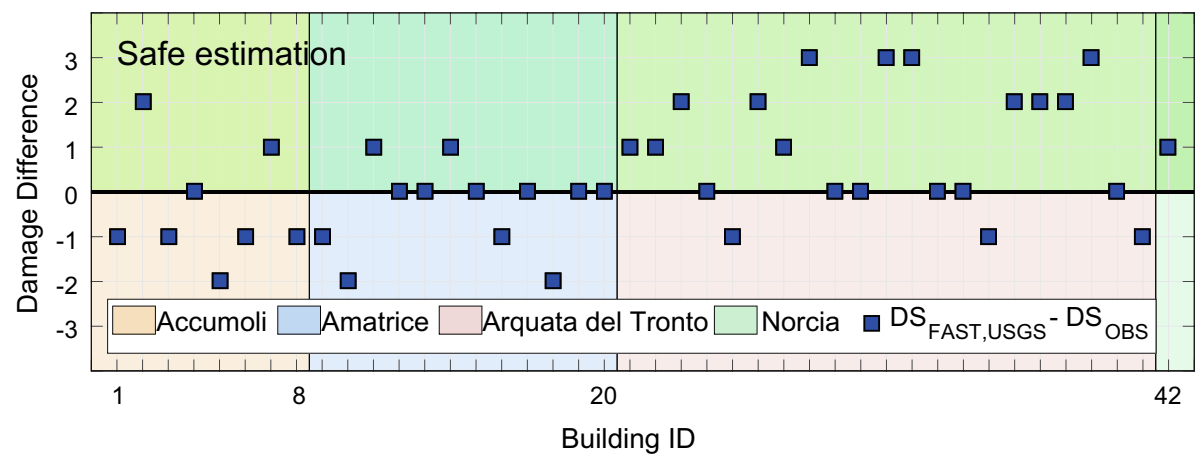

Fig. 13 Differences in damage estimation between FAST and observational data in the case of PGA demand evaluated as per the USGS shake-map of the August 24 event 


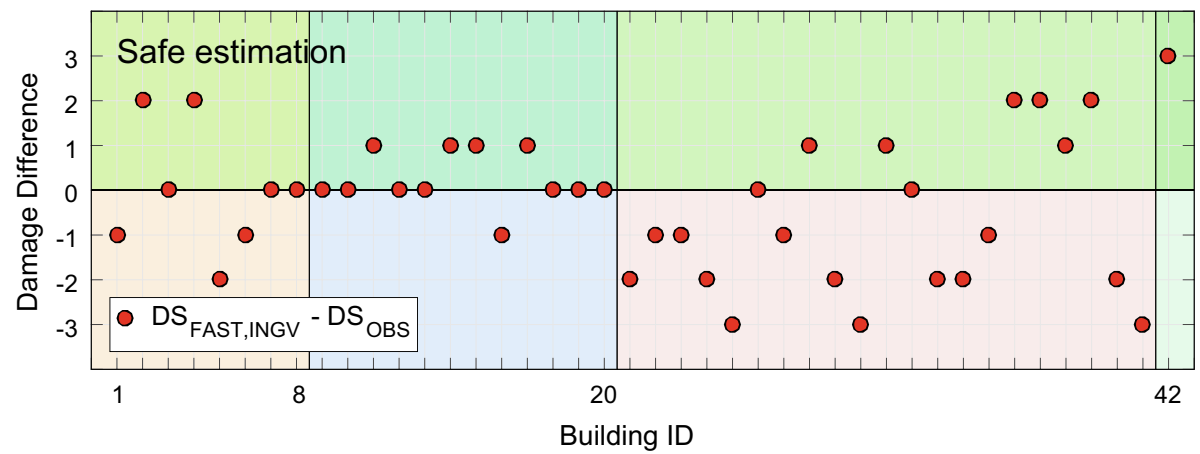

Fig. 14 Differences in damage estimation between FAST and observational data in the case of PGA demand evaluated as per INGV shake-map of the August 24 event

(see Fig. 3c compared to Fig. 3a) and by the fact that the sample of buildings in Arquata del Tronto includes many non-residential buildings very different from the regular infilled RC buildings for which FAST is currently calibrated (De Luca et al. 2015).

Observing the damage difference using the USGS PGA for Arquata del Tronto, it appears that FAST greatly overestimates the damage state, with nine buildings having a positive DS difference equal to two or greater. However, when looking at the buildings that had a positive difference of two DS or greater, they differ significantly from the typical buildings for which FAST is calibrated for, not complying with more than one of the method's basic hypotheses. As mentioned in Sect. 3, four of the buildings (Building ID 36-39, Fig. 7c, d) were industrial buildings, and also a multi-residential building (Building ID 28) was present in the data set (see Fig. 15b). The industrial buildings have concrete infills, while Building ID 28 is very irregular in elevation with presence of RC structural walls. In all these cases FAST predicted two or more damage grades greater than their actual DS state as per rapid survey carried out during the EEFIT mission (EEFIT 2016). One of the critical assumptions of FAST is that the construction is a roughly regular infilled $\mathrm{RC}$ frame; as in the sample of building on which it was calibrated from the area of Pettino after L'Aquila earthquake (De Luca et al. 2015).

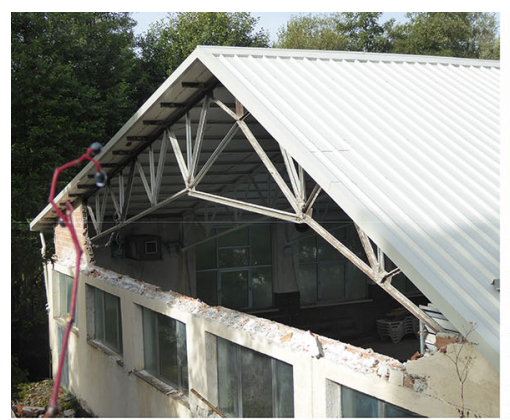

(a)

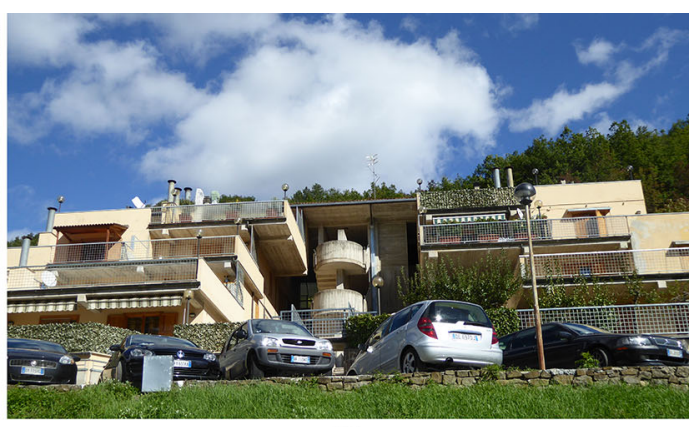

(b)

Fig. 15 a Building ID 16 in Amatrice, Lat. 42,37,21.420N Long. 13,17,33.160E; b Building ID 28 in Arquata del Tronto, Lat. 42,46,27.570N Long. 13,18,0.828E; Source EEFIT (2016) 
Other buildings with higher damage than that estimated by FAST were built on slopes. As an example, in Arquata del Tronto, there is building ID 41 (Fig. 16a), built on a slope, for which FAST underestimated the DS by one grade.

In general, for Accumoli, FAST did not produce satisfactory results for either shakemap. This may be because the station for Accumoli was not operative during the earthquake and the shake-map does not provide a robust estimate in the municipality, or the spectral scale factor does not account for the actual recorded shaking in the area. On the other hand, also for this area some buildings were not compliant with the basic hypotheses of FAST. An example is Building ID 5 (Fig. 16b) that is a precast one-storey RC structure with clay infills and an interstorey height definitely higher with respect to the average of $3.0 \mathrm{~m}$ assumed. In both cases, FAST estimates a lower damage level (i.e., - 2), potentially caused by the inaccurate conversion of IDR into $S_{d}$ through the interstorey height of the building.

For the cases in which the building typology matches the hypothesis of FAST, damage estimation is very well-matched as in the case of Amatrice. It is worth noting that in this study all the variables employed in FAST were assumed as deterministic not including the uncertainty related to them as it was made in De Luca et al. (2015). As an example, the IDR thresholds at each damage state can be characterized with very high coefficient of variations and sampled with a Monte Carlo simulation done for each building. This probably had not changed the central estimates as shown in Figs. 13 and 14, but could have better characterized the epistemic uncertainty of the methodology. On the other hand, the current one-to-one comparison is a powerful way to assess the impact of the demand scenario, the cases in which the methodology provides an accurate response and those for which a further calibration of the input variables is needed. This is evidently a result that could have not been discussed only analysing the aggregated comparison presented in Fig. 12, that is the natural result presentation for a methodology like FAST.

\section{Conclusion}

Data on 42 RC buildings gathered during the 2016 EEFIT Central Italy Earthquake Reconnaissance mission were used firstly to derive empirical fragility curves and secondly to test whether the FAST calibration by De Luca et al. (2015) for the 2009 L'Aquila

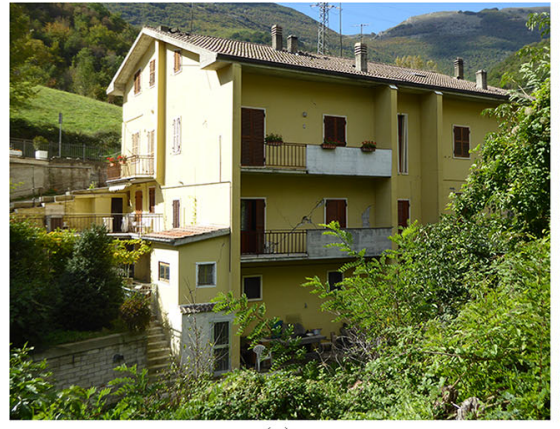

(a)

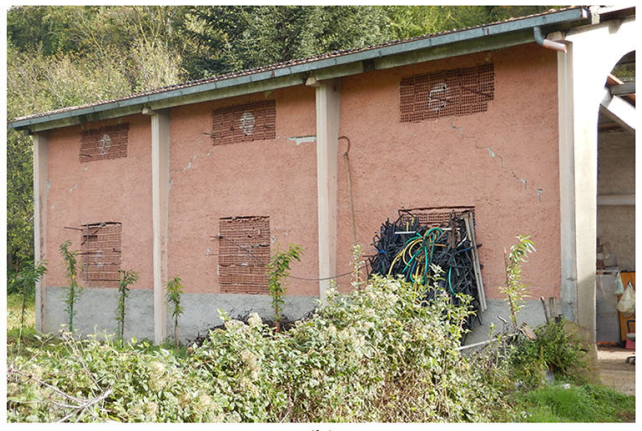

(b)

Fig. 16 a Building ID 41 in Arquata, Long. 42,46,33.64N Lat. 13,17,37.88E; b Building ID 5 in Grisciano (Accumoli municipality), Long. 42,43,51.57N Lat. 13,16,11.676E; Source EEFIT (2016) 
earthquake is applicable to the RC building stock and the earthquake that struck Central Italy on the 24th of August 2016. Data were collected through the EEFIT Rapid Visual Survey and buildings were located using a Geographical Information System software package to compile the database of RC infilled buildings. This included information on their Damage State (DS) using the European Marcoseismic Scale, number of storeys, shape in plan and estimated Peak Ground Acceleration according to the USGS and INGV shakemaps. Observational fragilities from the dataset were generated for damage grades one to three and compared to those generated for the L'Aquila earthquake in two other studies, aimed at establishing a first comparison between damage data. The observational fragility for DS2 was within the $95 \%$ confidence interval to the one estimated by De Luca et al. (2015) for L'Aquila, but due the small sample size these new fragilities cannot be considered reliable alone. The new observational fragilities were then employed for the Bayesian update of L'Aquila fragilities, using the consolidated formulation for lognormal prior and lognormally distributed new data (e.g., Miano et al. 2016) in a new fashion very suitable for integrating information from different earthquakes in the same area. The posterior fragilities, updated with 2016 data and based on the USGS shake-map, resulted in a lower vulnerability estimation of damage states two and three for RC buildings in the area. This result is in line with recent findings of other studies (Douglas et al. 2015) recalling a trend of underestimation of damage in RC buildings for L'Aquila when using scenarios based on non-refined shake-maps like the USGS one. The Bayesian update of L'Aquila fragility curves resulted in an adjustment of the median PGA at the three DS considered (slightly reducing the median PGA for DS1 and increasing by $10-15 \%$ the median PGA for DS2 and DS3). A significant reduction of the logarithmic standard deviations of the posterior fragilities is also obtained. This application provides a valuable approach for the integration of empirical fragilities derived for the same region.

Data gathered was used to run FAST analysis on the buildings using the methods' variables calibrated by De Luca et al. (2015) for L'Aquila earthquake. The predicted damage state was evaluated for the USGS and INGV shake-map demands of the event. The two shake-maps are different in terms of accuracy: the INGV one includes manual revision of data and fault information (Faenza et al. 2016). Damage differences in the two FAST applications was mainly caused by the inherent difference of the shakemap demands. The PGA demands from INGV provided accurate FAST predictions for the Municipality of Amatrice but not for Accumoli or Arquata del Tronto. The PGA demand from USGS produced a safe FAST damage prediction in $70 \%$ of cases, that is a very satisfactory result considering that the method is meant to be used in the aftermath of earthquake events for prioritization purposes when shake-maps are not yet updated and refined. On the other hand, the results also show that the FAST method, as calibrated in De Luca et al. (2015), can be used to predict damage states for roughly regular-in-plan buildings with clay hollow brick infills, similar to those in the sample used for the calibration in L'Aquila region, but it needs additional calibration for its successful employment in the case of RC buildings with infills of other materials.

Acknowledgements This work is funded by the Natural Environment Research Council (NE/P01660X/1). The underlying data are owned by EEFIT (www.eefit.org.uk), and all deposited in the EEFIT ftp site. They can be obtained upon request to eefit@istructe.org.

Open Access This article is distributed under the terms of the Creative Commons Attribution 4.0 International License (http://creativecommons.org/licenses/by/4.0/), which permits unrestricted use, distribution, and reproduction in any medium, provided you give appropriate credit to the original author(s) and the source, provide a link to the Creative Commons license, and indicate if changes were made. 


\section{References}

American Society of Civil Engineers, ASCE (2007) Seismic rehabilitation of existing buildings, ASCE/SEI 41-06. Reston, Virginia

Ang AH, Tang WH (1984) Probability concepts in engineering planning and design, vol. 2: decision, risk, and reliability. Wiley, New York, NY, p 608

Asteris PG, Antoniou ST, Sophianopoulos DS, Chrysostomou CZ (2011) Mathematical macromodeling of infilled frames: state of the art. J Struct Eng 137(12):1508-1517

Bing Aerial Map (2016) https://www.bing.com/maps/aerial. Accessed 21 Mar 2017

Calvi GM (1999) A displacement-based approach for vulnerability evaluation of classes of buildings. J Earthq Eng 3(3):411-438

CEN (2004) European standard EN1998-1:2004. Eurocode 8: design of structures for earthquake resistance. Part 1: general rules, seismic actions and rules for buildings. Comité Européen de Normalisation, Brussels

Crowley H, Pinho R, Bommer JJ (2004) A probabilistic displacement-based vulnerability assessment procedure for earthquake loss estimation. Bull Earthq Eng 2(2):173-219

D'Ayala D, Worth J, Riddle O (2009) Realistic shear capacity assessment of infill frames: comparison of two numerical procedures. Eng Struct 31(8):1745-1761

De Luca F, Verderame GM (2013) A practice-oriented approach for the assessment of brittle failures in existing reinforced concrete elements. Eng Struct 48:373-388

De Luca F, Verderame GM (2015) Seismic vulnerability assessment: reinforced concrete structures. In: Beer M, Patelli E, Kougioumtzoglou I, Au S-K (eds) Encyclopedia of earthquake engineering. Section Editors Fatemeh Jalayer and Carmine Galasso

De Luca F, Verderame GM, Manfredi G (2013) FAST vulnerability approach: a simple solution for damage assessment of RC infilled buildings. In: Actas del Vienna congress on recent advances in earthquake engineering and structural dynamics, 28-30 August, Vienna, Austria

De Luca F, Verderame GM, Gómez-Martínez F, Pérez-García A (2014) The structural role played by masonry infills on RC building performances after the 2011 Lorca, Spain, earthquake. Bull Earthq Eng 12(5):1999-2026

De Luca F, Verderame GM, Manfredi G (2015) Analytical versus observational fragilities: the case of Pettino (L'Aquila) damage data database. Bull Earthq Eng 13(4):1161-1181

Decreto Ministeriale n. 40 del 3/3/1975 (1975) Approvazione delle norme tecniche per le costruzioni in zone sismiche. G.U. n. 93 dell'8/4/1975. (in Italian)

Decreto Ministeriale (DM) 24/1/1986 (1986) Istruzioni relative alla normativa tecnica per le costruzioni in zona sismica. G.U. n. 108 del 12/5/1986. (in Italian)

Decreto Ministeriale (DM) 16/1/1996 (1996) Norme tecniche per le costruzioni in zone sismiche. G.U. n. 29 del 5/2/1996. (in Italian)

Decreto Ministeriale (DM) 14/1/2008 (2008) Approvazione delle nuove norme tecniche per le costruzioni. G.U. n. 29 del 4/2/2008. (in Italian)

Del Gaudio C, Ricci P, Verderame GM (2017) First remarks about the expected damage scenario following the 24th August 2016 earthquake in central Italy. In: Proceedings of the 16th world conference on earthquake engineering, 9-13 January, Santiago, Chile, paper ID 5005

Demo Istat (2016) Dato Istat-popolazione residente al 30 giugno 2016. Accessed 21 Mar 2017

Dolšek M, Fajfar P (2004) Inelastic spectra for infilled reinforced concrete frames. Earthq Eng Struct Dyn 33(15):1395-1416

Douglas J, Climent DM, Negulescu C, Roullé A, Sedan O (2015) Limits on the potential accuracy of earthquake risk evaluations using the L'Aquila (Italy) earthquake as an example. Ann Geophys 58(2):S0214. https://doi.org/10.4401/ag-6651

EEFIT (2016) [online]. See https://eefitamatrice.wordpress.com/. Accessed 21 Mar 2017

EERI (2016) Central Italy earthquake clearinghouse [online]. http://www.eqclearinghouse.org/2016-08-24italy/. Accessed 21 Mar 2017

Ellul F, D’Ayala D (2012a) Realistic FE models to enable push-over non linear analysis of masonry infilled frames. Integration 10(1):1

Ellul F, D'Ayala D (2012b) Realistic FE models to enable push-over non linear analysis of masonry infilled frames. Open Constr Build Technol J 6(SPEC. ISS. 1):213-235. https://doi.org/10.2174/ 1874836801206010213

Engineering, International Association of Earthquake Engineering (IAEE), Tokyo

Ercolino M, Magliulo G, Manfredi G (2016) Failure of a precast RC building due to Emilia-Romagna earthquakes. Eng Struct 118:262-273 
Erdik M, Fahjan Y (2006) Damage scenarios and damage evaluation. In: Oliveira CS, Roca A, Goula X (eds) Assessing and managing earthquake risk, chapter 10. Springer, Berlin

Faenza L, Lauciani V, Michelini A (2016) The ShakeMaps of the Amatrice, M6, earthquake. Ann Geophys 59:1-8. https://doi.org/10.4401/ag-7238

Fardis MN (1997) Experimental and numerical investigations on the seismic response of RC infilled frames and recommendations for code provisions. Report ECOEST-PREC8 no. 6. Prenormative research in support of eurocode 8

FEMA (2012) Next-generation methodology for seismic performance assessment of buildings. In: Prepared by the applied technology council for the federal emergency management agency, Report No. FEMA P-58, Washington, DC

Fiorato AE, Sozen MA, Gamble WL (1970) An investigation of the interaction of reinforced concrete frames with masonry filler walls. Report no. UILU-ENG 70- 100. Urbana-Champaign (IL): University of Illinois

Galasso C, Maddaloni G, Cosenza E (2014) Uncertainly analysis of flexural overstrength for capacity design of RC beams. J Struct Eng 140(7):04014037

GEER (2016) 2016 Central Italy earthquake [online]. http://www.geerassociation.org/component/geer_ reports/. Accessed 21 Mar 2017

Gómez-Martínez F, Pérez-García A, De Luca F, Verderame GM (2014) Generalized FAST approach for seismic assessment of infilled RC MRF buildings: application to the 2011 Lorca earthquake. WIT Trans Built Environ 141:427-443

Grünthal G (1998). European macroseismic scale 1998 (EMS-98). European Seismological Commission, Subcommission on Engineering Seismology, Working Group Macroseismic Scales. Conseil de l'Europe. Cahiers du Centre Européen de Géodynamique et de Séismologie, p 15

Iervolino I, Manfredi G, Polese M, Verderame GM, Fabbrocino G (2007) Seismic risk of R.C. building classes. Eng Struct 29(5):813-820

INGV (2017) Istituto Nazionale di Geofisica e Vulcanologia. http://www.ingv.it/it/. Accessed 21 Mar 2017

Jaiswal K, Wald D, D’Ayala D (2011) Developing empirical collapse fragility functions for global building types. Earthq Spectra 27(3):775-795

Jalayer F, De Risi R, Manfredi G (2015) Bayesian cloud analysis: efficient structural fragility assessment using linear regression. Bull Earthq Eng 13(4):1183-1203

Kappos AJ (2000) Seismic design and performance assessment of masonry infilled RC frames. In: Proceedings of the 12th world conference on earthquake

Lai CG, Foti S, Rota M (2009) Input sismico e stabilità geotecnica dei siti di costruzione (vol 6). IUSS Press, Pavia

Liel AB, Lynch KP (2012) Vulnerability of reinforced-concrete-frame buildings and their occupants in the 2009 L'Aquila, Italy, earthquake. Nat Hazards Rev 13(1):11-23

Luzi L, Puglia R, Russo E, ORFEUS WG5 (2016) Engineering strong motion database, version 1.0. Istituto Nazionale di Geofisica e Vulcanologia, Observatories and Research Facilities for European Seismology. https://doi.org/10.13127/ESM

Malhotra PK (2006) Smooth spectra of horizontal and vertical ground motions. Bull Seismol Soc Am 96(2):506-518

Manfredi G, Prota A, Verderame GM, De Luca F, Ricci P (2014) 2012 Emilia earthquake, Italy: reinforced concrete buildings response. Bull Earthq Eng 12(5):2275-2298

Miano A, Jalayer F, De Risi R, Prota A, Manfredi G (2016) Model updating and seismic loss assessment for a portfolio of bridges. Bull Earthq Eng 14(3):699-719

Michelini A, Faenza L, Lauciani V, Malagnini L (2008) ShakeMap implementation in Italy. Seismol Res Lett 79(5):688-697

Ordinanza del Presidente del Consiglio dei Ministri n. 3274 del 20/3/2003 (2003) Primi elementi in materia di criteri generali per la classificazione sismica del territorio nazionale e di normative tecniche per le costruzioni in zona sismica. G.U. n. 105 dell' $8 / 5 / 2003$. (in Italian)

Ordinanza del Presidente del Consiglio dei Ministri n. 3431 del 3/5/2005 (2005) Ulteriori modifiche ed integrazioni all'ordinanza del Presidente del Consiglio dei Ministri n. 3274 del 20 marzo 2003. G.U. n. 107 del 10/5/2005. (in Italian)

Porter K, Hamburger R, Kennedy R (2007a) Practical development and application of fragility functions. In: Structural engineering research frontiers, pp 1-16. https://doi.org/10.1061/40944(249)23

Porter K, Kennedy R, Bachman R (2007b) Creating fragility functions for performance-based earthquake engineering. Earthq Spectra 23(2):471-489

Porter K, Jaiswal K, Wald DJ, Greene M, Comartin C (2008) 'WHE-PAGER project: a new initiative in estimation global building inventory and its seismic vulnerability. In: Proceedings of 14th world conference on earthquake engineering, Beijing, China 
Relief Web (2017) CEDIM forensic disaster analysis group and CATDAT and earthquake-report.com http:// reliefweb.int/sites/reliefweb.int/files/resources/italia.pdf. Accessed 21 Mar 2017

Ricci P, De Luca F, Verderame GM (2011) 6th April 2009 L'Aquila earthquake, Italy: reinforced concrete building performance. Bull Earthq Eng 9(1):285-305

Rossetto T, Elnashai A (2003) Derivation of vulnerability functions for European-type RC structures based on observational data. Eng Struct 25(10):1241-1263

Rossetto T, Ioannou I, Grant DN (2013) Existing empirical fragility and vulnerability relationships: compendium and guide for selection. GEM Foundation, Pavia

Sarabandi P, Pachakis D, King S, Kiremidjian A (2004) Empirical fragility functions from recent earthquakes. In: Proceedings of 13th world conference on earthquake engineering, Vancouver, Canada

Singhal A, Kiremidjian AS (1998) Bayesian updating of fragilities with application to RC frames. ASCE J Struct Eng 124(8):922-929

USGS (2017) U.S. geological survey, [online]. See https://www.usgs.gov/. Accessed 21 Mar 2017

Vamvatsikos D, Cornell CA (2006) Direct estimation of the seismic demand and capacity of oscillators with multi-linear static pushovers through incremental dynamic analysis. Earthq Eng Struct Dyn 35(9):1097-1117

Verderame GM, De Luca F, De Risi MT, Del Gaudio C, Ricci P (2012) A three level vulnerability approach for damage assessment of infilled RC buildings: the Emilia 2012 case (V 1.0). http://www.reluis.it

Verderame GM, Ricci P, De Luca F, Del Gaudio C, De Risi MT (2014) Damage scenarios for RC buildings during the 2012 Emilia (Italy) earthquake. Soil Dyn Earthq Eng 66:385-400

Wald DJ, Worden CB, Quitoriano V, Pankow KL (2006) ShakeMap ${ }^{\circledR}$ Manual, technical manual, users guide, and software guide. Available at http://pubs.usgs.gov/tm/2005/12A01/pdf/508TM12-A1.pdf. p 156

Yamaguchi N, Yamazaki F (2001) Estimation of strong motion distribution in the 1995 Kobe earthquake based on building damage data. Earthq Eng Struct Dyn 30(6):787-801 